\title{
AUTOMATION OF BRIDGE CONSTRUCTION BY PRECAST SPAN METHOD IN KOREA HIGH SPEED RAILWAY PROJECT
}

\author{
Sung-Il KIM ${ }^{1)}$, Young-Nam LEE $^{2)}$, In-Sup KIM ${ }^{3)}$, Won-Pyo LEE ${ }^{4)}$ \\ ${ }^{1)}$ Ph.D, Hyundai Institute of Construction Technology, blands@hdec.co.kr \\ ${ }^{2)}$ Ph.D, Director, Hyundai Institute of Construction Technology \\ ${ }^{3)}$ Director, Hyundai Engineering \& Construction \\ ${ }^{4)}$ Ph.D, Chief Researcher, Hyundai Institute of Construction Technology
}

\begin{abstract}
Large portion of Kyung-bu high-speed railway in Korea was constructed in the form of bridges or tunnels. Most of bridges were designed to be prestressed continuous concrete box girder type. The precast span method was selected for the construction of prestressed concrete box girder bridges for its merits of good quality, fast construction speed, low construction cost and safety. Since it was the first attempt to apply the precast span method to a continuous bridge for high speed railway, many design and construction details were studied and implemented in the construction.
\end{abstract}

Keyword : High Speed Railway, Automation, Continuous Bridge, Precast Span Method

\section{Introduction}

It was inevitable to construct many bridges and tunnels in high-speed railway lines due to topographical characteristics of Korea. Out of $412 \mathrm{~km}$ long Kyung-bu high-speed railway, $302 \mathrm{~km}$ long section was designed in the form of either bridge or tunnel. Half of $19.5 \mathrm{~km}$ long Hyundai's construction site (Section 2-2), shown in Figure 1, was also composed of bridges and tunnels.

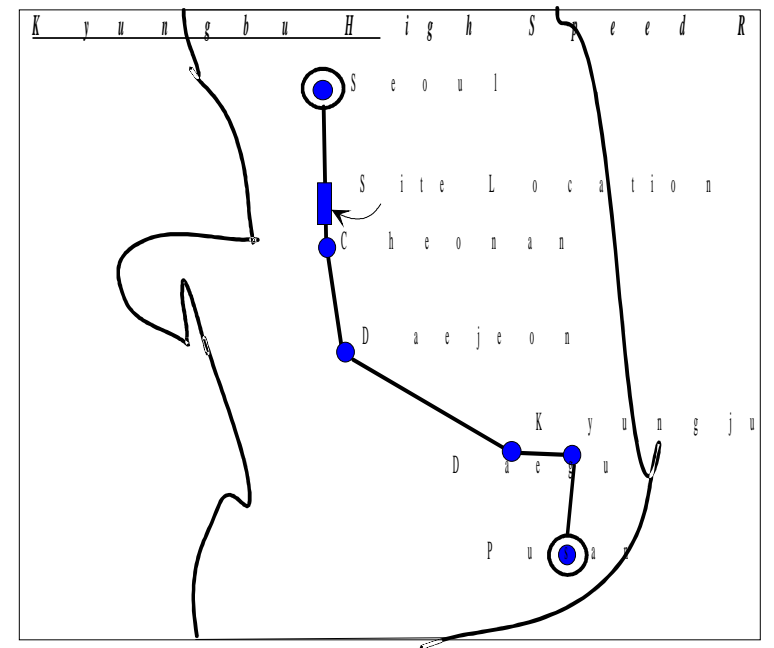

Fig. 1 Site Location
Most of bridges were designed to be prestressed concrete box girder type, considering economy and safety. For the construction of 3 prestressed concrete box girder bridges $(69 \%$ of total bridge length in Section 2-2), the precast span method (PSM) was adopted instead of the original plan of using movable scaffolding system (MSS). The PSM was favored because of good quality of bridge section secured by factory manufacturing, fast construction speed (1.5 2 days per span in comparison with 25 30 days of the MSS), low construction cost with mechanized construction and the safety of field workers. The PSM was composed of three main processes : producing a segment of complete concrete box girder, transporting the segment to the site using heavy trailer, and placing the segment on predetermined piers using launching gantry.

So far, PSM has been applied for the construction of simple span bridges mainly. However, new application of PSM for continuous bridge construction has been made, considering advantages of a continuous bridge in dynamic behavior under moving high-speed train and maintenance cost. In this paper, design and construction of a continuous bridge construction using PSM will be described briefly. 

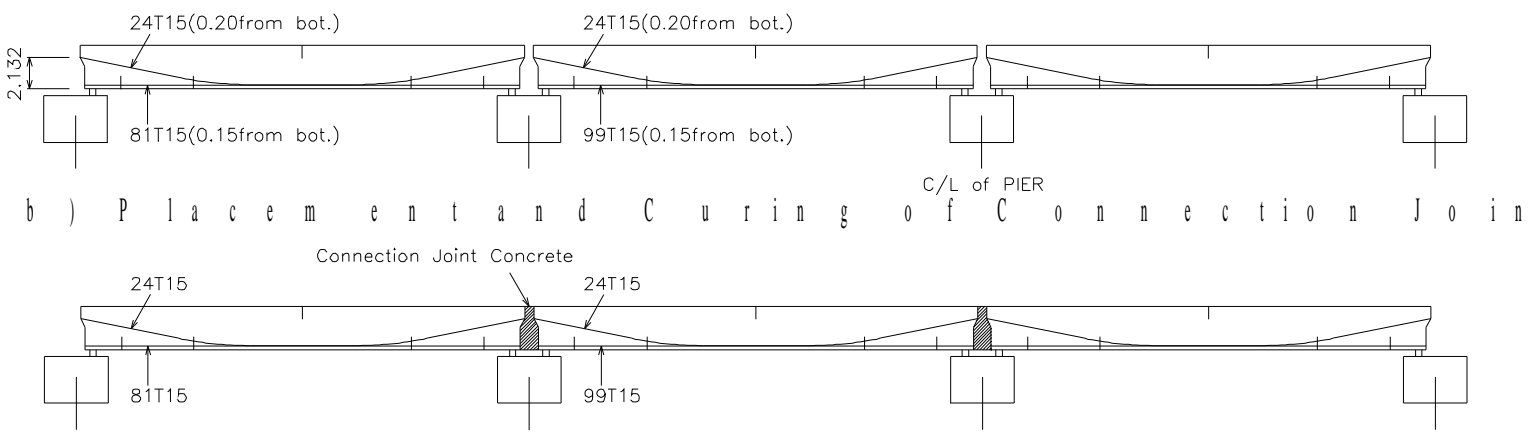

c) C C o n
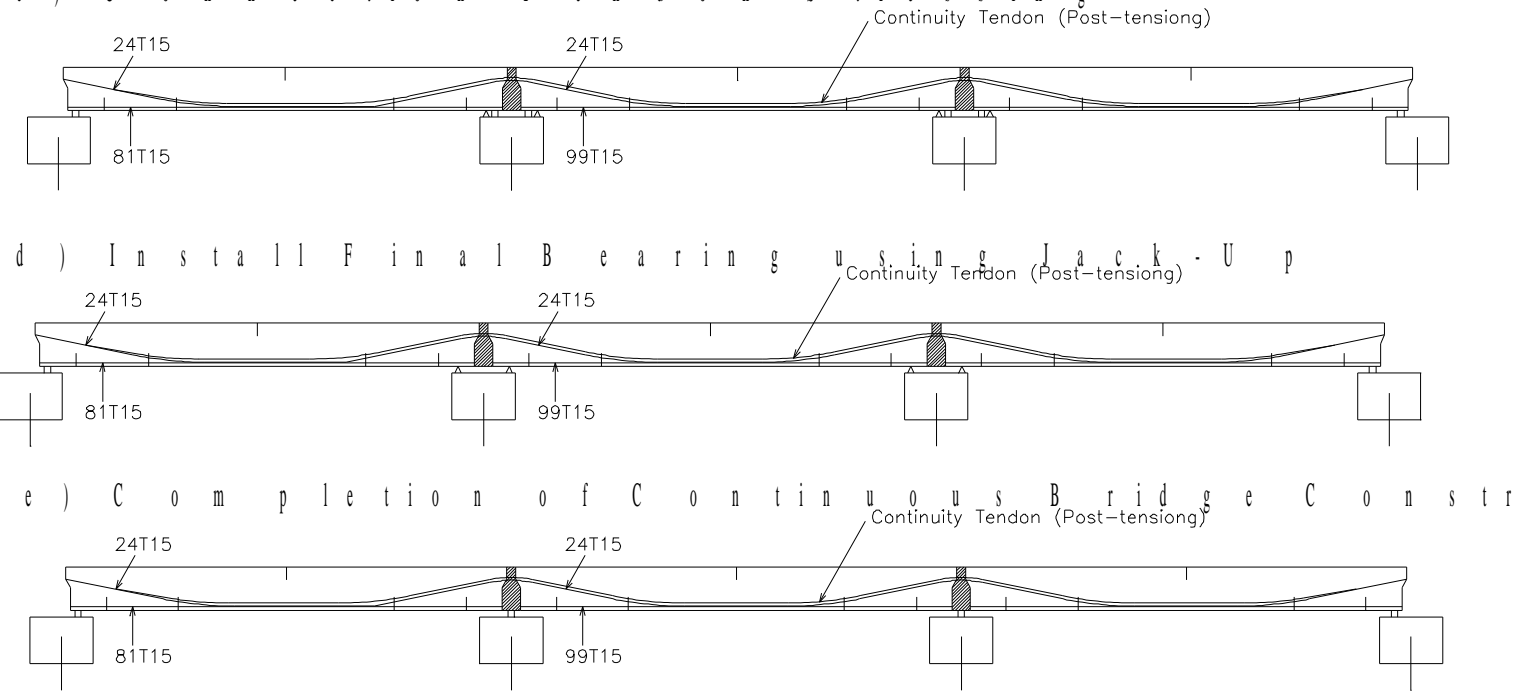

Fig.2 Continuation Process of Simple Span

Regarding the construction of continuous bridges using PSM, the continuation process of simple spans, shown in Figure 2, was studied thoroughly before the construction. It was expected that the bridge would experience many changes in structural system, load conditions during each construction step and change in support conditions were considered carefully in design stage. The capacity and movement of bearings to be used were also studied in advance ${ }^{[2],[6]}$.

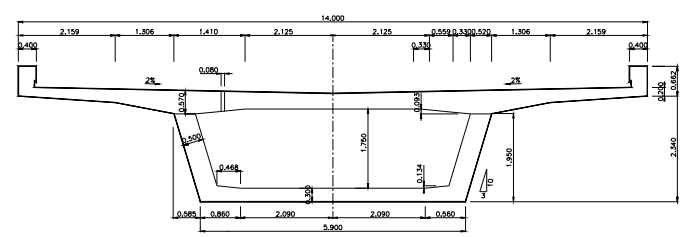

(a) Center Span

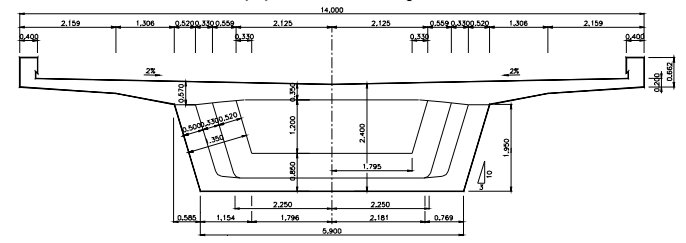

(b) End Span

Fig.3 Typical Cross Section

Considering the erection device available and economical efficiency, the span length was determined to be $25 \mathrm{~m}^{[6]}$. Figure 3 shows typical cross sections of prestressed concrete box girder.

Since a high-speed train would run at the maximum speed of $350 \mathrm{~km} / \mathrm{h}$, careful consideration was given to the dynamic behavior of bridge under moving highspeed train loads, and passenger comports. Trackstructure interaction analysis was also performed for the safety of high-speed train and the bridge ${ }^{[3],[4],[5]}$.

\section{Construction}

The installation procedure of a prestressed concrete box girder segment is shown in Figure 4. After producing a segment of complete prestressed concrete box girder bridge (span length $25 \mathrm{~m}$ and weight 600t) in factory, the segment was transported to the site using $110 \mathrm{t}$ heavy trailer and placed on predetermined piers using launching gantry (Figure 5). Figure 6 shows the construction view of these procedures. 

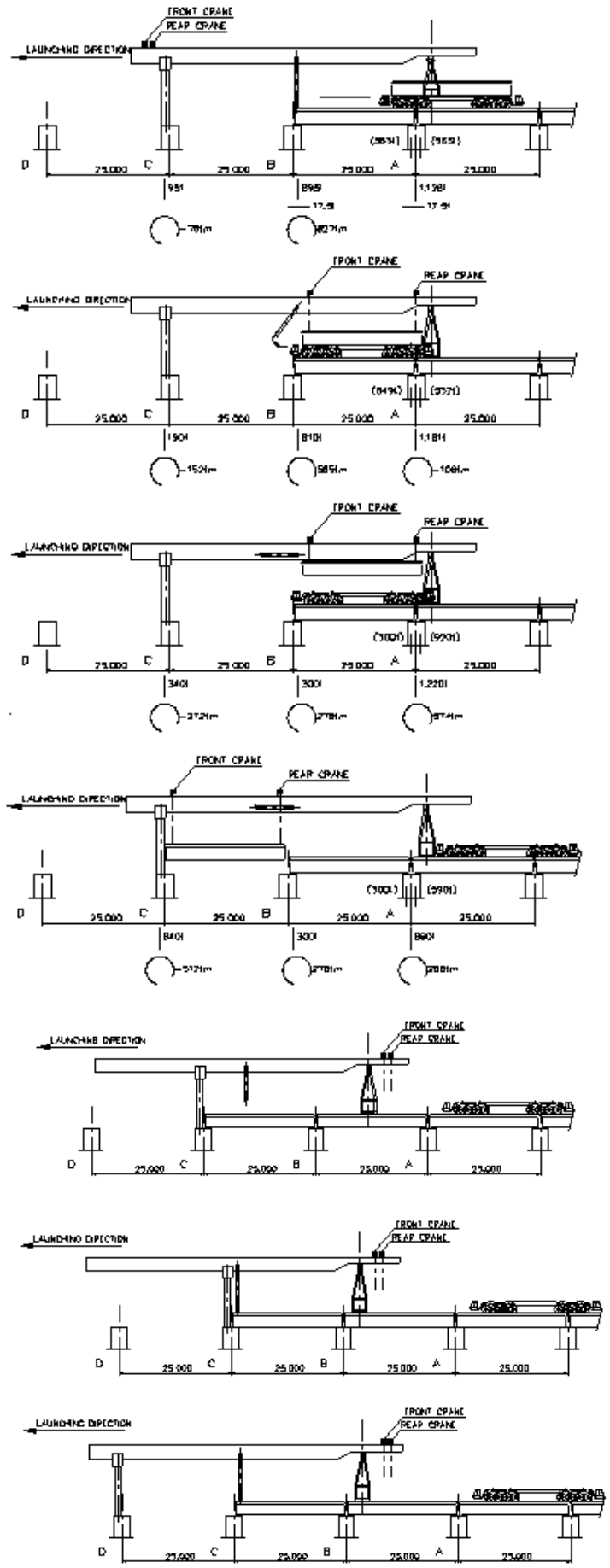

Fig. 4 Installation of PC Box Girder

Simple span sections were connected to a 3-span continuous bridge system by placing connection joint concrete, prestressing connection tendon and replacing temporary bearings with permanent bearings (Figure 2). Figure 7 and Figure 8 show the flow of the continuation process and the cross section of continuation details with sheath pipe. For each connection joint, three sheath couplers were used for connection of two pieces of sheath pipes, forming one row and three or four rows of sheath pipes were provided, as shown in Figure 8.
Post-tensioning was performed when the strength of the concrete reached $300 \mathrm{~kg} / \mathrm{cm}^{2}$. After posttensioning, prudent control of elongation quantity was made.

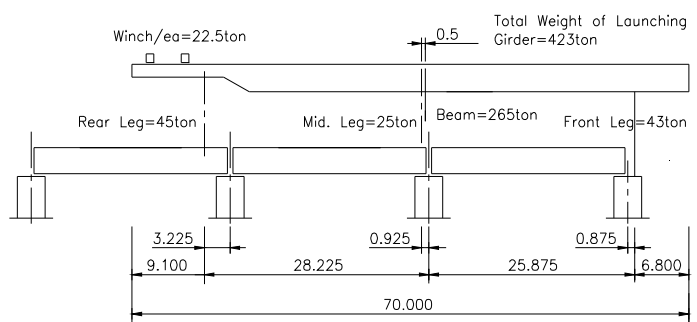

Fig. 5 Launching Gantry
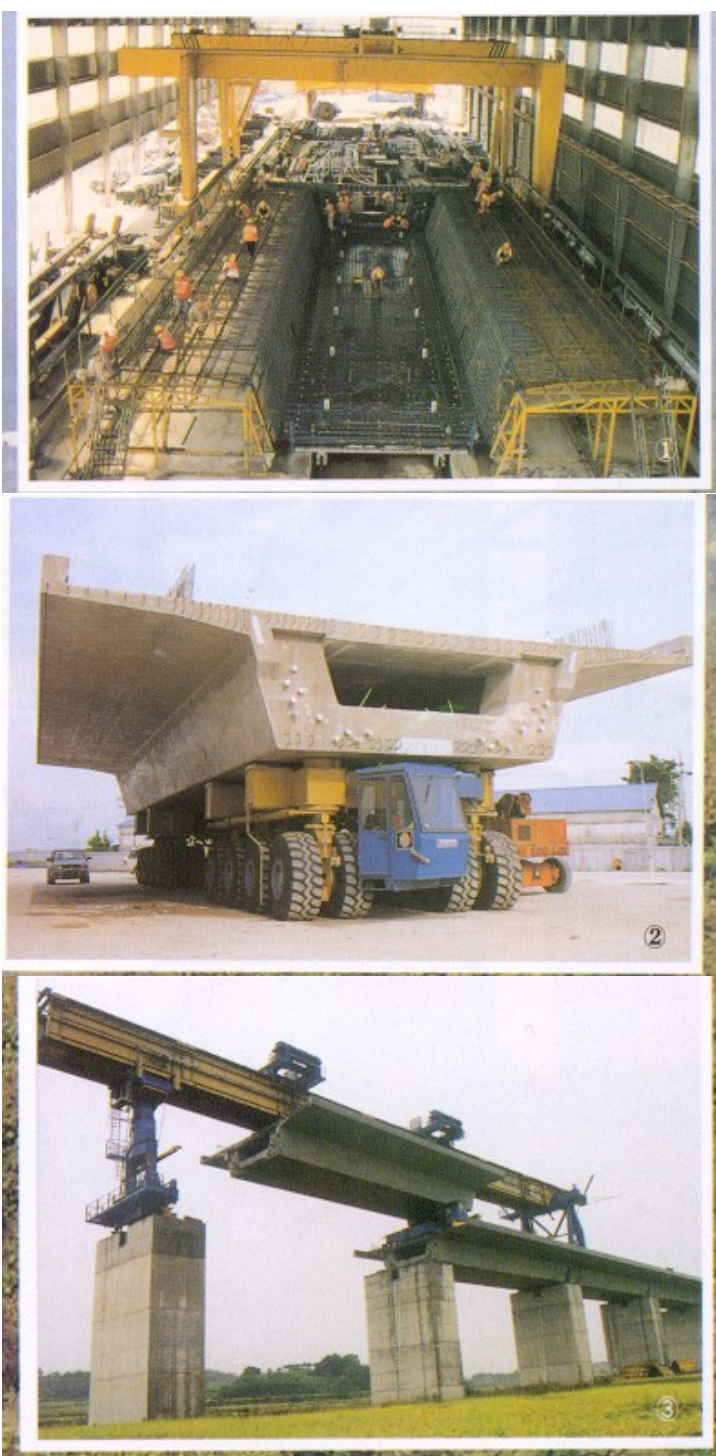

Fig. 6 Construction View

In early construction stages, many construction problems such as breakage of tendon, corrosion of tendon, hydration heat, temporary bearing material and damage of sheath pipe were encountered and solved ${ }^{[6]}$ 


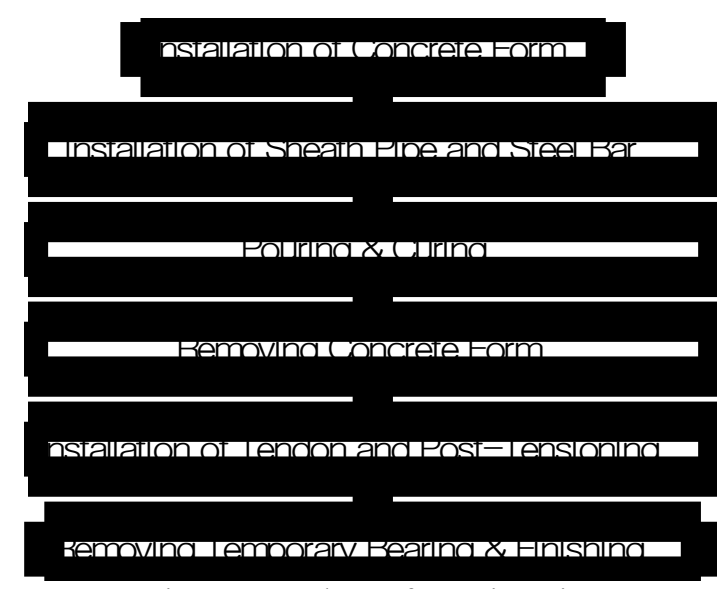

Fig. 7 Procedure of Continuation

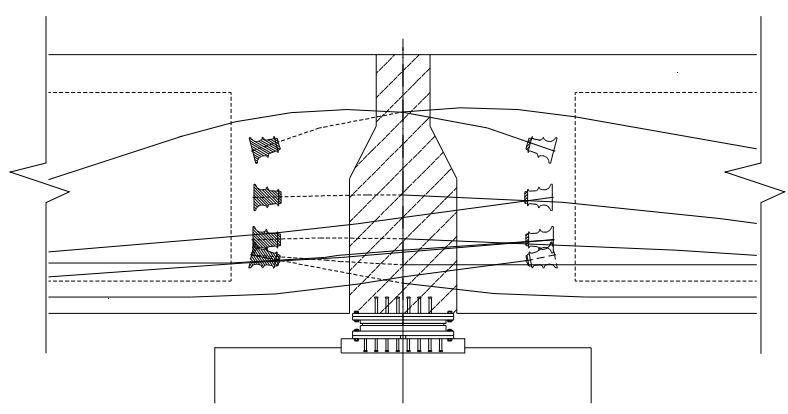

Fig.8 Cross Section of Continuation Segment

\section{Conclusion}

In this paper, design and construction of continuous bridges using the precast span method have been described briefly.

Design and construction details of structural system under different construction steps were investigated and implemented in the design drawings.

Since it was the first attempt to apply the precast span method to a continuous bridge for high speed railway, many design and construction details were studied and implemented in the construction.

By adopting the precast span method, good quality, fast construction speed, low construction cost and the safety were obtained with mechanized automation system.

\section{REFERENCES}

[1] Korea High Speed Rail Construction Authority, Bridge Design Manual (BRDM) - Final Report, 1995.6

[2] Systra, Precast Span Method - Detailed Structure Design, 1997.1

[3] Seoul National University, Report : Rational Design and Construction Method for Precast Span Method Bridge, 1997.6

[4] Seoul National University, Report : Evaluation of Fatigue Resistance of PSM Box Girder Bridges,
1998.1

[5] Systra, Dynamic Analysis Under High Speed Live Loads, 1995.8

[6] Hyundai Engineering \& Construction, Construction Plan (Continuation) - Kyung-bu High Speed Railway 2-2 Section, 1999.1 